\title{
High prevalence of HIV/AIDS risky sexual behaviors among street youth in gondar town: a community based cross sectional study
}

Negash Tadesse ${ }^{1}$, Tadesse Awoke Ayele ${ }^{2+}$, Zelalem Birhanu Mengesha ${ }^{3+}$ and Kefyalew Addis Alene ${ }^{4^{*}+}$

\begin{abstract}
Background: Street youth are vulnerable to HIV/AIDS and all kinds of health risks. This study assessed HIV/AIDS risky sexual behaviors and its predictors among street youth in Gondar town, Northwest Ethiopia.

Methods: A community based cross sectional study was conducted on 467 street youth living in Gondar town. A pre tested and structured questionnaire via interview was used to collect data. Logistic regression analysis was used to identify predictors. Odds ratio with $95 \% \mathrm{Cl}$ was computed to assess the strength of associations.

Results: A total of 288 (61.7\%) respondents had sexual intercourse in their life time. Among these 264 (91.7\%) had more than one lifetime sexual partners. In addition, $80.5 \%$ of them used condom inconsistently in the last 12 months. Khat chewing was found to be predictor of having multiple sexual partners. Rural former residence and longer duration of stay on the street are also identified as predictors of inconsistent condom use.

Conclusion: High prevalence of HIV/AIDS risky sexual behaviors were observed among street youth in Gondar town. Interventions aimed at reducing sexual risky behaviors among street youth should focus on reducing the duration of stay on the street and chat chewing.
\end{abstract}

Keywords: HIV/AIDS, Risky sexual behaviors, Street youth, Gondar

\section{Background}

Sub-Saharan Africa including Ethiopia has been highly affected by HIV and currently accounts for more than two thirds of recent HIV infections worldwide [1]. The overall adult HIV prevalence in Ethiopia has remained almost similar in the Ethiopia Demography and Health Survey (EDHS) 2005 and 2011 which was 1.4\% and 1.5\% respectively. The prevalence is higher in urban areas (4.2\%), where the street youth are living, than in rural areas $(0.6 \%)$. It is relatively high among young respondents who report two or more sexual partners $(6.7 \%)$ in the 12 months before the survey and among those who used a condom inconsistently $(2.4 \%)[2,3]$. This high rate of HIV infection in youth is fueled by the increased number of street youth. Studies revealed that HIV sero-

\footnotetext{
*Correspondence: kefadis@gmail.com

${ }^{\dagger}$ Equal contributors

${ }^{4}$ Department of Public Health Officer, Institute of Public health, College of Medicine and Health Sciences, University of Gondar, Gondar, Ethiopia
} Full list of author information is available at the end of the article prevalence rates for street youth are 10-25 times higher than other groups of adolescents [4].

The United Nations report estimated that about 150 million youth are homeless or spent most of their time on the street. The problem is becoming a worldwide phenomenon and majority of them live in large cities and urban areas of developing countries. Street youths are among the high risk, insecure and vulnerable groups to various forms of abuses and diseases. They are particularly exposed to HIV/AIDS $[5,6]$.

Urbanization, poverty, lack of family support, peer influences and absence of employment, which are common in developing countries, are the leading causes to street life. This increasing number of street youth is one of the most serious problems in Ethiopia [7]. According to UNICEF report, there are approximately 500,000700,000 street youth nationally [8]. Many of these street youth are found in streets of major towns like Gondar. They lives in conditions of sever deprivation which place them at all kind of health risks [9]. 
High risk sexual activities include unprotected sex, sex before legal consent and multiple sexual partners put youth at risk for teen pregnancy and sexual transmitted diseases. However, Risky sexual behaviors of street youth and its predictors in Gondar town have never been studied before. Therefore, this study was conducted to assess the prevalence of HIV/AIDS risky sexual behaviors and its predictors among street youths in Gondar town, Northwest Ethiopia.

\section{Methods}

A community based cross sectional study was conducted from March to April, 2011 in Gondar town. It is located about $750 \mathrm{~km}$ away from Northwest of Addis Ababa, the capital of Ethiopia. According to the 2007 census projection, the town has a total population of 227,100 [10]. Many young and poor Ethiopians come to the town from the nearby districts and live in the streets as beggars and shoe shiner.

The participants of this study were street youth aged 10-24 who have lived in Gondar town for at least six months. The definition of street youth in this study was taken from WHO's training module on substance use, sexual and reproductive health including HIV/AIDS and STDs. Street youth are defined as young people: who are 'of the street', having no home but the streets. Their family may have abandoned them or they may have no family member left alive. While who are 'on the street', are defined as those who visit their family regularly. They might even return every night to sleep at home, but spends most days and some nights on the street because of poverty, overcrowding, sexual or physical abuse at home [11]. For the purpose of this study, censes was first conducted to estimate the approximate number of street youth and identify their common place of residence. All the 467 street youth who live in Gondar town for at least six month on the street were included in this study.

Socio demographic data; sex, age, occupation, religion, former residence, educational level, occupation, and duration of stay on the street were collected. HIV/AIDS risky sexual behaviors of street youth were assessed using questionnaire adopted from Behavioral Surveillance Survey and other published articles which was modified to be applicable for the local context. Data were collected via interview using structured questionnaire which was first prepared in English and then translated to the local language Amharic. Pretest was done out of the study area and modifications were done accordingly. Data collectors were diploma nurses working at different health institutions of Gondar town. Training was given to the data collectors for two days on the objective, confidentiality of information, respondents right and techniques of interview prior to data collection. During data collection, frequent checkups were made by the principal investigator to ensure the completeness and consistency of the data.

The returned questionnaires were checked for completeness by the investigators. The data were entered in to EPI INFO version 3.5.3 and analyzed by SPSS version 16. Descriptive analysis was done to summarize the data in relation to the different variables.

Variables having $P$ value $\leq 0.2$ in the bivariate analysis were entered into multiple logistic regression model to control the effect of confounding. Odds ratio with their 95\% confidence intervals were calculated to measure associations, and statistical significance was set at $P<0.05$.

Ethical clearance was obtained from the ethical review board of Institute of Public Health, University of Gondar. The purpose and importance of the study were explained to the participants. Data were collected after full informed verbal consent was obtained from each participant. Confidentiality of the information has been maintained throughout by excluding names in the questionnaire and keeping their privacy by interviewing alone. They were also informed that participation was on voluntary basis and they can withdraw at any time if they are not comfortable about the interview.

\section{Results}

\section{Socio demographic characteristics of participants}

A total of 467 youth were interviewed. Of them, 268 (58.4\%) were on the street and 76 (16.3\%) were females. About half $(51.4 \%)$ of the respondents were in the age group of 15-19 years. Almost all (97.9\%) the study participants had some type of job on the street. Four hundred eight (89.5\%) were earning less than twenty Ethiopian Birr per day (about one USA dollar) [Table 1].

\section{Prevalence of HIV/AIDS risky sexual behaviors}

A total of $288(61.7 \%)$ respondents had sexual intercourse in their life time. Among these, 264 (91.7\%) had more than one lifetime sexual partner. Two hundred fifty two $(87.5 \%)$ of them had sexual intercourse in the past twelve months. Three fourth of sexually active males $(75 \%)$ had sexual intercourse with commercial sex workers in the past 12 months. Seventy four percent of sexually active youth had ever used condom. However, $80.5 \%$ of them used condom inconsistently in the last 12 months. The main reasons for not using were perceived reduction of sexual pleasure $(34.8 \%)$, followed by negligence to use condom (26.2\%) and too expensive to buy condom (12.3\%) [Table 2].

\section{Factors associated with HIV/AIDS risky sexual behaviors}

In the bivariate analysis, more than a year stay on the street and khat chewing were factors associated with having multiple sexual partners. In the multivariate 
Table 1 Socio demographic characteristics of street youth in Gondar town, Northwest Ethiopia 2011

\begin{tabular}{|c|c|c|}
\hline Variables & Number & Percent \\
\hline \multicolumn{3}{|l|}{ Type of street life } \\
\hline On the street & 268 & 58.4 \\
\hline Off the street & 199 & 41.6 \\
\hline \multicolumn{3}{|l|}{ Sex } \\
\hline Male & 391 & 83.7 \\
\hline Female & 76 & 16.3 \\
\hline \multicolumn{3}{|l|}{ Ethnicity } \\
\hline Amhara & 390 & 83.5 \\
\hline Tigray & 77 & 16.5 \\
\hline \multicolumn{3}{|l|}{ Age group } \\
\hline $10-14$ & 118 & 25.3 \\
\hline $15-19$ & 240 & 51.4 \\
\hline $20-24$ & 109 & 23.3 \\
\hline \multicolumn{3}{|l|}{ Religion } \\
\hline Orthodox Christian & 429 & 91.9 \\
\hline Muslim & 12 & 2.6 \\
\hline Others & 26 & 5.5 \\
\hline \multicolumn{3}{|l|}{ Former residence } \\
\hline Urban & 269 & 57.6 \\
\hline Rural & 198 & 42.4 \\
\hline \multicolumn{3}{|l|}{ Educational level } \\
\hline Illiterate & 151 & 32.3 \\
\hline Read and write only & 110 & 24 \\
\hline Primary school (1-8) & 184 & 39 \\
\hline Secondary School (9-12) & 22 & 4.7 \\
\hline \multicolumn{3}{|l|}{ *Occupation } \\
\hline Shoe shining & 40 & 11.6 \\
\hline Carrying items & 285 & 61.0 \\
\hline peddling & 53 & 11.3 \\
\hline Transferring message & 123 & 26.3 \\
\hline Washing cars & 90 & 19.3 \\
\hline Begging & 30 & 6.4 \\
\hline Sex for money & 61 & 13.0 \\
\hline \multicolumn{3}{|l|}{ Average income per day } \\
\hline Less than 20 birr & 418 & 89.5 \\
\hline Greater than 20 birr & 49 & 10.7 \\
\hline \multicolumn{3}{|l|}{ Duration on the street } \\
\hline Less than or equal to one year & 56 & 12.0 \\
\hline Greater than one year & 411 & 88.0 \\
\hline
\end{tabular}

*due to multiple answers the percentage is greater than $100 \%$.

analysis, Khat chewers were at higher risk of having multiple sexual partners than non chewers [AOR 6.509; 95\% CI: 2.494, 16.989] [Table 3].

Similarly, factors associated with inconsistent condom use were investigated using logistic regression. Those who stayed on the street for more than a year were more likely
Table 2 HIV/AIDS risky sexual behaviors of street youth in Gondar town, Northwest Ethiopia, 2011

\begin{tabular}{lll}
\hline Variables & Frequency & Percent \\
\hline Ever had sexual intercourse $\mathbf{n}=\mathbf{4 6 7}$ & 288 & 61.7 \\
\hline Yes & 179 & 38.3 \\
\hline No & & \\
\hline *Reason to have sex $\mathbf{n = 2 8 8}$ & 103 & 22 \\
\hline Personal desire & 38 & 8 \\
\hline Peer pressure & 54 & 11.5 \\
\hline Fell in love & 32 & 6.8 \\
\hline Influence of chat or alcohol & 13 & 2.7 \\
\hline Raped & 38 & 8.1 \\
\hline Marriage & 78 & 16.7 \\
\hline To get money & 2 & 0.4 \\
\hline Others & & \\
\hline Lifetime number of sexual partner $\mathbf{n = 2 8 8}$ & 24 & 8.3 \\
\hline One & 264 & 91.7 \\
\hline More than one & & \\
\hline
\end{tabular}

Sexual intercourse in the last 12 months

$\mathrm{n}=\mathbf{2 8 8}$

\begin{tabular}{cll}
\hline Yes & 252 & 87.5 \\
\hline No & 36 & 12.5 \\
\hline
\end{tabular}

Number of sexual partner in the last 12

months $n=252$

\begin{tabular}{lll}
\hline One & 70 & 27.8 \\
\hline More than one & 182 & 72.2
\end{tabular}

Ever use of condom $\mathbf{n}=\mathbf{2 8 8}$

\begin{tabular}{lll}
\hline Yes & 213 & 74 \\
\hline No & 75 & 26
\end{tabular}

Consistency condom use in the last 12

months $n=213$

\begin{tabular}{cll}
\hline Consistent & 41 & 19.5 \\
\hline Inconsistent & 172 & 80.5 \\
\hline
\end{tabular}

Reason for not to use condom in the last 12 months

\begin{tabular}{lll}
\hline Not available & 9 & 3.7 \\
\hline Too expensive & 30 & 12.3 \\
\hline Ashamed to ask my partner & 13 & 5.3 \\
\hline Partner objected & 15 & 6.1 \\
\hline Donot like it & 3 & 1.2 \\
\hline Reduce sexual satisfaction & 85 & 34.8 \\
\hline Ashamed to buy & 8 & 3.3 \\
\hline Negligence & 64 & 26.2 \\
\hline Others & 17 & 7.0
\end{tabular}

\section{Condom use during last sexual intercourse} $\mathrm{n}=\mathbf{2 1 3}$

\begin{tabular}{ccc}
\hline Yes & 103 & 48.3 \\
\hline No & 110 & 51.7 \\
\hline
\end{tabular}


Table 2 HIV/AIDS risky sexual behaviors of street youth in Gondar town, Northwest Ethiopia, 2011 (Continued)

\begin{tabular}{ccc}
\hline Sex with CSW in the last $\mathbf{1 2}$ months $\mathbf{n}=\mathbf{2 3 6}$ & & \\
\hline Yes & 177 & 75 \\
\hline No & 59 & 25 \\
\hline
\end{tabular}

*the percentage is greater than $100 \%$ because of multiple answers.

to have history of inconsistent condom use than those who stayed on the street for less than a year $(\mathrm{AOR}=4.365$, $95 \% \mathrm{CI} ; 1.801,10.582)$. Moreover, those who came from rural areas were more likely to have inconsistent condom use as compared to those who came from urban $[\mathrm{AOR}=$ 10.961, 95\% CI: 3.206, 37.473]. However, type of street life and khat chewing were not significantly associated with inconsistence condom use [Table 4].

\section{Discussion}

This study provided the opportunity to look at HIV/ AIDS related risk sexual behaviors among street youth in Gondar town, Northwest Ethiopia. It is found that out of the total street youth, $61.7 \%$ have ever had sexual initiation. Lack of psycho social support from parents, peer pressure, higher prevalence of substance abuse and being idle might be the possible reasons for this high prevalence of sexual initiation.

Among sexually active participants, high proportion (91.7\%) of respondents reported that they had multiple sexual partners which is high when compared with previous study done in Dessie town (80.6\%) [12]. This might be due to Gondar town is one of the tourist areas in Ethiopia that pose risk for having multiple sexual partners. The other reason could be the ten years time gap between the two studies. The life time prevalence of having multiple sexual partners was also high. Unstable life styles, higher level of exposure to sexual exploitation and sexual practice for means of survival due to economical problems can be the possible explanations.

Of sexually active youth, $74 \%$ had ever used condom and this was similar with a study conducted on street youth in Dessie town (73.8\%) [12]. Inconsistent condom use put youth at a higher risk for HIV/AIDS and other STIs. Majority of the respondents $(80.5 \%)$ were found to have history of inconsistent condom use. This might be

Table 3 Factors associated with having multiple sexual partners among street youth in Gondar town, Northwest Ethiopia, 2011

\begin{tabular}{|c|c|c|c|c|}
\hline \multirow[t]{2}{*}{ Variable } & \multicolumn{4}{|c|}{ Multiple sexual partner } \\
\hline & $\overline{\text { Yes }}$ & No & COR $(95 \% \mathrm{Cl})$ & AOR $(95 \% \mathrm{Cl})$ \\
\hline \multicolumn{5}{|l|}{ Type of street life } \\
\hline On the street type & 124 & 7 & 1.00 & 1.00 \\
\hline Off the street types & 140 & 17 & $0.465(0.187,1.158)$ & $0.529(0.159,1.758)$ \\
\hline \multicolumn{5}{|l|}{ HIV knowledge } \\
\hline Comprehensive & 46 & 1 & 1.00 & 1.00 \\
\hline Not comprehensive & 218 & 23 & $2.206(0.639,36.85)$ & $4.236(0.518,34.624)$ \\
\hline \multicolumn{5}{|l|}{ Average income per day } \\
\hline$\leq 20$ birr & 223 & 22 & 1.00 & 1.00 \\
\hline$>20$ birr & 41 & 2 & $2.022(0.458,8.932)$ & $2.567(0.489,13483)$ \\
\hline \multicolumn{5}{|l|}{ Former residence } \\
\hline Urban & 152 & 15 & 1.00 & 1.00 \\
\hline Rural & 112 & 9 & $1.228(0.519,2.907)$ & $1.367(0.505,3.698)$ \\
\hline \multicolumn{5}{|l|}{ Duration on the street } \\
\hline$\leq 1$ year & 100 & 4 & 1.00 & 1.00 \\
\hline$>1$ year & 164 & 20 & $0.328(0.109,0.987)$ & $0.228(0.045,1.17)$ \\
\hline \multicolumn{5}{|l|}{ Alcohol drinking } \\
\hline Never & 14 & 2 & 1.00 & 1.00 \\
\hline Yes & 250 & 22 & $1.623(0.347,7.606)$ & $0.565(0.104,3.061)$ \\
\hline \multicolumn{5}{|l|}{ Khat chewing } \\
\hline Never & 43 & 12 & 1.00 & 1.00 \\
\hline Yes & 221 & 12 & $5.140(2.166,12.198)$ & $6.509(2.494,16.989)$ \\
\hline \multicolumn{5}{|l|}{ Condom use practice } \\
\hline Consistent & 39 & 5 & 1.00 & 1.00 \\
\hline Inconsistent & 225 & 19 & $1.518(0.535,4.305)$ & $3.278(0.762,14.099)$ \\
\hline
\end{tabular}


Table 4 Factors associated with condom use among street youth in Gondar town, Northwest Ethiopia, 2011

\begin{tabular}{|c|c|c|c|c|}
\hline \multirow{3}{*}{ Variables } & \multicolumn{4}{|c|}{ Inconsistent } \\
\hline & \multicolumn{4}{|c|}{ Condom use practice } \\
\hline & Yes & No & COR $(95 \% \mathrm{Cl})$ & AOR $(95 \% \mathrm{Cl})$ \\
\hline \multicolumn{5}{|l|}{ Type of street life } \\
\hline On the street types & 99 & 32 & 1.00 & 1.00 \\
\hline Off the street types & 145 & 12 & $3.906(1.918,7.952)$ & $1.626(0.662,3.998)$ \\
\hline \multicolumn{5}{|l|}{ Former residency } \\
\hline Urban & 126 & 41 & 1.00 & 1.00 \\
\hline Rural & 118 & 3 & $12.799(3.859,7.952)$ & $10.961(3.206,37.473)$ \\
\hline \multicolumn{5}{|l|}{ Income per day } \\
\hline$\leq 20$ birr & 211 & 211 & 1.00 & 1.00 \\
\hline$>20$ birr & 33 & 10 & $532(0.240,1.177)$ & $0.386(0.146,1.021)$ \\
\hline \multicolumn{5}{|l|}{ Duration on the street } \\
\hline$\leq 1$ year & 73 & 31 & 1.00 & 1.00 \\
\hline$>1$ year & 171 & 13 & $5.586(2.765,11.285)$ & $4.365(1.801,10.582)$ \\
\hline \multicolumn{5}{|l|}{ Multiple sexual partners } \\
\hline No & 19 & 5 & 1.00 & 1.00 \\
\hline Yes & 225 & 225 & $1.518(0.535,4.305)$ & $1.733(0.471,6.375)$ \\
\hline \multicolumn{5}{|l|}{ Khat chewing } \\
\hline Never & 41 & 14 & 1.00 & 1.00 \\
\hline Yes & 203 & 30 & $2.311(1.127,4.736)$ & $1.973(0.82,4.745)$ \\
\hline \multicolumn{5}{|l|}{ HIVknowledge } \\
\hline Comprehensive & 201 & 40 & 1.00 & 1.00 \\
\hline Not comprehensive & 43 & 4 & $2.139(0.727,6.295)$ & $3.454(0.051,11.343)$ \\
\hline
\end{tabular}

due to lack of knowledge about condom use. Consistent with a study done in Ethiopia [13], Khat chewing was significantly associated with having multiple sexual partners. This may be a result of the physiological effects of khat and its active element [14]. Amphetamine and amphetamine-like substances such as khat bring about negative physical and physiological effects by causing the continual release of neurotransmitters, like norepinephrine and particularly dopamine. Norepinephrine increased sympathethic nervous system activity, which alerts the system of the body to react instinctively to emergency situations and to have a role in initiating sex drive. Again the association between khat chewing and multiple sexual partners may be explained through social, physiological or individual mechanisms [15-17]. A study showed that khat chewers are also alcohol drunker [13]. Alcohol may reduce judgment and behavior via physiological or socially learned mechanisms. In addition to this, a youth's personal characteristics or social environment by itself may lead to risky sexual activity and initiation of new sexual partnership [18].

Duration of stay on the street had influence on inconsistent condom use. Participants who stayed on the street for more than a year were more likely to have history of inconsistent condom use. This finding is important for the planning of strategies related to the reduction of inconsistent condom use that are important to avoid unintended pregnancies and STDs including HIV AIDS. Similarly, another study done in Dessie town reported significant association between duration of stay and inconsistent condon use. In the present study, the use of condom inconsistently at last sexual relation was also much more frequent among youth who came from rural areas. The high rate of inconsistent condom use in this study was an indication of the fact that high risk sexual behaviors were widely practiced by the study group in Gondar town. This calls for a well organized information, education and communication effort to bring about behavioral change.

This study has the following strengths: the study has focused on marginalized and neglected group of people who are highly vulnerable to HIV and other STIs where adequate information and studies are lacking. This might certainly fill some of the knowledge gaps and serve as a base line information for future studies. The questionnaire used was adopted partly from the Behavioral Surveillance Survey tool (BSS) and from the previously published papers. In addition, high response rate was the other strength of this study. However, the difficulty to discuss sexual matter in face to face interview might bring social desirability bias though the survey 
was done anonymously by arranging same sex interviewer. Underreporting may have occurred, as some questions were of a sensitive nature.

\section{Conclusion}

This study finding showed that high number of street youth had multiple sexual partners and the practice of inconsistent condom use was very high. Khat chewing was found to be significantly associated with having multiple sexual partners. Duration of stay on the street and former residence out of Gondar town were factors significantly associated with inconsistent use of condoms. Information education communication or behavioral change communication campaigns and reducing the duration of stay on the street are important recommendations to reduce the occurrence of risky sexual behaviors among street youth.

\section{Competing interests}

The authors declare that they have no competing interests.

\section{Authors' contributions}

$N T, Z B, T A$, and KA participated in all steps of the study from its commencement to write up. They have reviewed and approved the submission of the manuscript.

\section{Acknowledgments}

We would like to acknowledge the University of Gondar for financial support. Our deepest gratitude also goes to those who participated in this study.

\begin{abstract}
Author details
${ }^{1}$ Family Health International Ethiopia, Addis Ababa, Ethiopia. ${ }^{2}$ Department of Epidemiology and Biostatistics, Institute of Public Health, College of Medicine and Health Sciences, University of Gondar, Gondar, Ethiopia. ${ }^{3}$ Department of Reproductive Health and Health Education, Institute of Public Health, College of Medicine and Health Sciences, University of Gondar, Gondar, Ethiopia. ${ }^{4}$ Department of Public Health Officer, Institute of Public health, College of Medicine and Health Sciences, University of Gondar, Gondar, Ethiopia.
\end{abstract}

Received: 8 February 2013 Accepted: 10 June 2013

Published: 15 June 2013

\section{References}

1. UNAIDS, WHO: Joint United Nations Programme on HIV/AIDS (UNAIDS). AIDS epidemic update 2009, 9(1700):09-36.

2. CSA: Ethiopia Demographic and Health Survey 2011. Addis Ababa, Ethiopia: entral Statistical Agency [Ethiopia] and ICF International; 2012.

3. Central Statistical Agency EaOM: Ethiopia Demographic and Health Survey 2005. Addis Ababa, Ethiopia: Central statistical agency of Ethiopia; 2006.

4. Tadelle G: Sexuality and HIV/AIDS risk and perception, among male street youths in dessie. North East Afr Stud 2000, 7(1):109-126.

5. Burns A, Daileader C, Finger W, Murphy-Graham E, McCarney R, Schueller J: Reaching Out-of-School Youth with Reproductive Health and HIVIAIDS Information and Services. USA: Family Health International; 2004.

6. John Z: Homelessness increasing all over the world. The Washington Times. USA: The Washington Times; 2005.

7. Mazengia F, Worku A: Age at sexual inititation and factors associated with it among youth in Northeast Ethiopia. Ethiop J Health Dev 2009, 23(2):154-162.

8. UNICEF: Annual report for Ethiopia. Addis Ababa: UNICEF; 2010

9. Shah S, Graidage G, Valencia J: Youth on the streets: the importance of social interactions on psychosocial well-being in an African context. New York: Better Care Network; 2005.

10. Comission FPC: Summary and Statistical Report of the 2007 population and housing census of Ethiopia. Addis Ababa: CSA; 2008:57-60.
11. WHO: Working with street children: A Training Package on Use, sexual and reproductive health including HIV/AIDS and STDs (Module 1). Geneva: WHO; 2000.

12. Yimam E: Assessment of reproductive health behavior and needs of street youth in dessie town, amhara region. Addis Ababa: Addis Ababa University; 2007.

13. Abebe D, Debella A, Dejene A, Degefa A, Abebe A, Urga K, Ketema L: Khat chewing habit as a possible risk behaviour for HIV infection: A case-control study. Ethiop J Health Dev 2005, 19(3):174-181.

14. Gilman A, Rall T, Nies A, Taylo P: Goodman \& Gilman's: The Pharmacological basis of therapeutics, vol. I and II. New York: Pergamon Press; 1991.

15. Lowry R: Substance use and HIV-related sexual behaviors among U.S. high school students: are they related? American J of Public Health 1994, 84(7):1116-1120.

16. Halpern-Felsher B, Millstein S, Ellen J: Relationship of alcohol use and risky sexual behavior: a review and analysis of findings. $J$ of Adolescent Health 1996, 19(5):331-336.

17. Fortenberry J: Adolescent substance use and sexually transmitted diseases risk: a review. J of Adolescent Health 1995, 16(4):304-308.

18. Last JM: "Scope and Methods of Prevention," Public Health and Preventive Medicine. Norwalk: CT: Appleton Century Crofts; 1986.

\section{doi:10.1186/1756-0500-6-234}

Cite this article as: Tadesse et al.: High prevalence of HIV/AIDS risky sexual behaviors among street youth in gondar town: a community based cross sectional study. BMC Research Notes 2013 6:234.

\section{Submit your next manuscript to BioMed Central and take full advantage of:}

- Convenient online submission

- Thorough peer review

- No space constraints or color figure charges

- Immediate publication on acceptance

- Inclusion in PubMed, CAS, Scopus and Google Scholar

- Research which is freely available for redistribution 